\title{
Resection and heated pleural chemoperfusion in patients with thymic epithelial malignant disease and pleural spread: A single-institution experience
}

\author{
Alon Yellin, MD, ${ }^{\text {a }}$ David A. Simansky, MD, ${ }^{\mathrm{a}}$ Ronny Ben-Avi, MD, ${ }^{\mathrm{a}}$ Marina Perelman, MD, \\ Nona Zeitlin, MD, ${ }^{a}$ Yael Refaely, MD, ${ }^{a}$ and Alon Ben-Nun, MD ${ }^{\mathrm{a}}$
}

Objective: Our objective was to evaluate whether resection and heated pleural chemoperfusion (HPCP) is an effective treatment for de novo stage IVa thymoma (DNT) and thymic carcinoma (TC) and for thymoma with pleural relapse (TPR).

\begin{abstract}
Methods: A retrospective study was conducted of patients undergoing resection and HPCP in 1 center. HPCP with cisplatinum \pm doxorubicin (adriamycin) was performed for 60 minutes using a standard roller pump and a modified heat exchanger to a maximal intrapleural temperature of $43^{\circ} \mathrm{C}$. Follow-up included at least 1 annual computed tomographic scan until death or March 2012.
\end{abstract}

\begin{abstract}
Results: Thirty-five patients, 17 DNT, 14 TPR, and 4 TC, completed 42 intended treatments and were followed up for 4 to 202 months (median, 62 months). Seven patients had repeated HPCP at an interval of 2 to 12 years. There was no systemic toxicity. Ninety-day mortality was $2.5 \%$. Major and minor morbidity occurred in $12 \%$ each. Five-, 10-, and 15-year overall survivals for DNT, TPR, and TC were $81 \%, 73 \%, 58 \%$ (DNT), 67\%, 56\%, $28 \%$ (TPR), and $0 \%, 0 \%, 0 \%$ (TC). Five- and 10-year progression-free survival was $61 \%, 43 \%$ for DNT and $48 \%, 18 \%$ for TPR. Presently, 11 of 17 DNT patients are alive (6, no evidence of disease), and 8 of 14 TPR are alive (6, no evidence of disease). Median survival for thymoma was 157 months. Overall survival was unrelated to any preoperative or intraoperative variable. Progression-free survival was improved in R0 compared with R1-2 resection $(P<.001)$. Local control achieved in $21(57 \%)$ of 37 procedures in thymoma patients was related only to completeness of resection $(P=.015)$.
\end{abstract}

Conclusions: (1) Lung-sparing resection and HPCP is feasible and safe. (2) In thymoma with pleural spread it offers excellent survival despite moderate pleural control. (3) Preliminary results with stage IVa TC are disappointing. (J Thorac Cardiovasc Surg 2013;145:83-9)

Thymic epithelial tumors (TET) are relatively uncommon neoplasms, the majority of which are discovered in early operable stages. About $7 \%$ of thymomas present at de novo stage IVa thymoma (DNT) and are associated with 5- and 10-year survivals of $59 \%$ and $36 \%$, respectively. ${ }^{1}$ Thymic carcinoma (TC) is a rare tumor, presenting usually at advanced stages and associated with a poor prognosis. Although the relapse rates for stage I-III thymoma are relatively low, ${ }^{1}$ more than $50 \%$ of these occur in the pleural space (thymoma with pleural relapse, TPR) and thereafter have an unfavorable fate. ${ }^{2,3}$

The literature pertaining to TET with pleural spread, whether de novo or recurrent, is limited. The condition has

\footnotetext{
From the Departments of Thoracic Surgery ${ }^{\mathrm{a}}$ and Pathology, ${ }^{\mathrm{b}}$ Sheba Medical Center, Tel Hashomer, Israel.

Disclosures: Authors have nothing to disclose with regard to commercial support.

Read at the 92nd Annual Meeting of The American Association for Thoracic Surgery, San Francisco, California, April 28-May 2, 2012.

Received for publication March 26, 2012; revisions received Sept 13, 2012; accepted for publication Oct 2, 2012; available ahead of print Oct 29, 2012.

Address for reprints: Alon Yellin, MD, Department of Thoracic Surgery, Sheba Medical Center, Tel Hashomer, Israel 52621 (E-mail: ayellin@sheba.health.gov.il). $0022-5223 / \$ 36.00$

Copyright (C) 2013 by The American Association for Thoracic Surgery http://dx.doi.org/10.1016/j.jtcvs.2012.10.013
}

been treated with chemotherapy alone ${ }^{4}$ but, more often, in a multimodality manner that almost always includes surgery. ${ }^{5,6}$ The surgical arm varies from debulking ${ }^{7,8}$ to radical and, occasionally, as extensive as pleuropneumonectomy ${ }^{9,10}$ or extrapleural pneumonectomy. ${ }^{11,12}$ Owing to the small cohorts of TET with pleural spread and the versatility of treatment options, the preferred approach for this condition has not been established.

Dissatisfied with the reported results and our own experience and learning from experience with pleural chemotherapy in mesothelioma and malignant effusions, ${ }^{13-15}$ we embarked as early as 1995 on a new management protocol consisting of surgical resection plus heated pleural chemoperfusion (HPCP). Preliminary reports with a small group of patients were reported in $2001 .^{16,17}$ The current study aims to analyze the operative results and the long-term outcome of a relatively large cohort in an attempt to verify whether it could be recommended as an acceptable treatment for TET with pleural spread.

\section{PATIENTS AND METHODS}

Included in this study are all patients with TET and pleural spread who underwent surgery plus HPCP since 1995. They were either referred 


\section{Abbreviations and Acronyms \\ DNT $=$ de novo stage IVa thymoma \\ HPCP $=$ heated pleural chemoperfusion \\ $\mathrm{TC}=$ thymic carcinoma \\ TET $=$ thymic epithelial tumor \\ $\mathrm{TPR}=$ thymoma with pleural relapse}

selectively by other institutions or taken from our own pool, in which case all patients with pleural spread were discussed in a multidisciplinary meeting. Patients $(n=2)$ with major chest wall involvement were considered unsuitable for this treatment. Data were acquired from a prospective database and, when necessary, admission charts were pulled and reviewed. Follow-up information was gathered from outpatient records, telephone conversations, and the national demographic registry. The study was approved by the institutional ethics committee and the off-label use of the chemotherapeutic agents by the institutional pharmacologic board.

Follow-up was scheduled at 6-month intervals and computed tomographic scans were performed at a minimum of 1 annually. Other studies like positron emission tomography-computed tomography, magnetic resonance imaging, octreotide scans, and biopsy were ordered on an individual basis.

Histologic material was revised by an experienced thoracic pathologist (M.P.) using hematoxylin and eosin stain and classified according to the 2004 World Health Organization. "Mixed thymomas" were designating by the predominant cell type, which comprised more than $50 \%$ of the submitted sections.

The number of pleural implants (from 2 to infinite) and the total implant volume $\left(1-350 \mathrm{~mL}^{3}\right)$ were recorded for every procedure.

\section{Preoperative and Postoperative Treatments}

All of the TC patients and 13 of the 31 thymoma patients received chemotherapy at some point before HPCP, with a response rate of $88 \%$. We have not used chemotherapy intentionally in a neoadjuvant setting. Full details as to the exact agents and doses are lacking, inasmuch as those were administered in many institutions. Radiation therapy was used in 8 TPR patients after their initial operation.

Adjuvant chemotherapy was administered to patients with TC or to thymoma patients with pleural R2 resection. Adjuvant radiotherapy was used in DNT patients with R1-R2 resection of their mediastinal component. In other patients, these modalities were reserved for the management of local or systemic relapses on an individual need to treat basis.

\section{Surgical Approach}

Surgery was aimed toward complete resection of any mediastinal involvement and gross resection of all pleural disease. Partial pleurectomy was performed mainly on the chest wall pleura. Diaphragmatic implants were removed along with partial muscle thickness when required. Visceral pleural implants were removed locally or by wedge excision. Pneumonectomy was avoided as far as possible. In this report R1 and R2 resection were grouped together as incomplete resection.

\section{Chemoperfusion}

Perfusion was performed in a routine manner described by us previously. ${ }^{13}$ In essence, it was done in the supine position after final closure of the incision, using $228 \mathrm{~F}$ chest tubes connected to a standard roller pump and a heat exchanger, which was modified in 1999 to allow an output of $45^{\circ} \mathrm{C}$. The amount of perfusate varied from 1500 to $3500 \mathrm{~mL}$. The perfusion was initiated without the chemotherapeutic agents. When the temperature stabilized, $100 \mathrm{mg} / \mathrm{m}^{2}$ of cisplatinum and since 2002 also a 50 to $60 \mathrm{mg}$ total dose of doxorubicin were added. Perfusion was carried out for 60 minutes at a flow of 1000 to $2500 \mathrm{~mL} / \mathrm{min}$. Pleural temperature was considered as the mean of the input and output temperatures as determined by earlier studies with an intrapleural temperature probe. Flow rates were adjusted as required to maintain the set temperature and hemodynamic stability. Renal protection was accomplished with adequate preperfusion hydration and maintaining a urine output of more than $80 \mathrm{~mL} / \mathrm{h}$.

On 2 occasions, HPCP was delayed for a few days owing a very lengthy operation associated with hemodynamic instability.

\section{Statistical Analysis}

Survival analysis was performed by the Kaplan-Meier method and was calculated from the date of the first HPCP using SPSS software (SPSS, Inc, Chicago, Ill). We used the term disease-free progression rather than disease-free survival because it is doubtful whether $\mathrm{R} 0$ resection can indeed be achieved in stage IVa TET unless extrapleural pneumonectomy is performed. For morbidity and mortality figures the denominator used was the number of operations. To examine combined effects of various factors on overall and progression-free survival and on local control, we used nonparametric tests, that is, $\chi^{2}$ and Mann-Whitney.

\section{RESULTS}

Forty patients were considered for surgery and HPCP. Five were rejected: 2 owing to TC histology (after midterm analysis of the early experience), 2 because of major chest wall involvement, and 1 intraoperatively owing to complete macroscopic and microscopic pleural response. The remaining 35 patients were divided into 3 groups: TC $(\mathrm{n}=4)$, DNT $(\mathrm{n}=17)$, and TPR $(\mathrm{n}=14)$. The demographic and clinical parameters are summarized in Table 1. The majority of thymoma patients had B2 histology and 15 $(48.4 \%)$ had myasthenia gravis at diagnosis.

Reoperation was performed in 11 patients with disease progression, of whom 4 did not continue to HPCP owing to liver metastases $(n=1)$, minute space $(n=1)$, single implant $(\mathrm{n}=1)$, and hemodynamic instability $(\mathrm{n}=1)$. The data pertaining to these 7 patients (redo HPCP) were added to Table 2, which summarizes the surgical and perfusion results. As a group, they were obviously older (mean age, 55 years) than the 35 "original cohort."

\section{Mortality and Morbidity}

The 90-day mortality was $2.5 \%$ (1 patient) owing to empyema complicating a redo operation 14 years after the initial HPCP. Another patient died 11.5 months after pneumonectomy, superior vena cava resection and reconstruction, and partial resection of both atria from a bronchopleural fistula. Nonfatal complications occurred after 11 procedures: DNT, 3; TPR, 4; TC, 2; and redo, 2 (27\%), including grade III/IV nausea $(\mathrm{n}=3)$, prolonged air leak $(\mathrm{n}=2)$, bleeding requiring reexploration $(\mathrm{n}=1)$, and pneumonia $(\mathrm{n}=1)$, all occurring in the early postoperative period. Delayed morbidity consisted of myasthenic crisis $(\mathrm{n}=2)$, chronic respiratory failure $(\mathrm{n}=1)$, and purulent pericarditis with sepsis $(\mathrm{n}=1)$. The later was the sole patient who had supraventricular tachycardia. 
TABLE 1. Patient characteristics $(n=35)$

\begin{tabular}{|c|c|c|c|}
\hline & DNT & TPR & TC \\
\hline Patients (no.) & 17 & 14 & 4 \\
\hline \multicolumn{4}{|l|}{ Age $(y)$} \\
\hline Median & 52 & 44 & 50 \\
\hline Range & $22-67$ & $25-62$ & $20-70$ \\
\hline Gender, male/female & $14: 3$ & $8: 6$ & $3: 1$ \\
\hline \multicolumn{4}{|l|}{ Histology } \\
\hline $\mathrm{AB}$ & & 2 & \\
\hline B1 & 2 & 3 & \\
\hline $\mathrm{B} 2$ & 12 & 5 & \\
\hline B3 & 3 & 4 & \\
\hline $\mathrm{TC}$ & & & 4 \\
\hline Myasthenia gravis & 6 & 9 & 0 \\
\hline Diagnosis-HPCP interval (median) & $6 w k$ & $4 y$ & $8 \mathrm{mo}$ \\
\hline Previous chemotherapy (response) & $9(8)$ & $5(4)$ & $4(3)$ \\
\hline Previous radiation & 2 & 8 & 0 \\
\hline \multicolumn{4}{|l|}{ Previous surgery } \\
\hline Resectional & 2 & 14 & 1 \\
\hline Diagnostic & 4 & & \\
\hline \multicolumn{4}{|l|}{ Side } \\
\hline Right & 7 & 4 & 3 \\
\hline Left & 9 & 10 & 1 \\
\hline Bilateral & 1 & & \\
\hline
\end{tabular}

$D N T$, De novo stage IVa thymoma; $T P R$, thymoma with pleural relapse; $T C$, thymic carcinoma; HPCP, heated pleural chemoperfusion.

There was no hematologic, renal, neurologic, or cardiac toxicity.

\section{Long-Term Outcomes}

Thymic carcinoma. Local control was achieved in none of the patients in this group and all died within 4 years (mean, 33 months) of distant disease spread despite aggressive systemic therapy (Figure 1).

TABLE 2. Surgical and perfusion data $(n=41)$

\begin{tabular}{|c|c|c|c|c|}
\hline & $\begin{array}{c}\text { DNT } \\
(\mathbf{n}=17)\end{array}$ & $\begin{array}{c}\text { TPR } \\
(n=14)\end{array}$ & $\begin{array}{c}\text { Redo } \\
(n=7) \\
\end{array}$ & $\begin{array}{c}\text { TC } \\
(n=4) \\
\end{array}$ \\
\hline \multicolumn{5}{|l|}{ Maximum procedure } \\
\hline Local resection & 4 & 5 & 3 & 1 \\
\hline Pleurectomy & 2 & 6 & & 1 \\
\hline Wedge/lobectomy & $3 / 1$ & 1 & 2 & \\
\hline Chest wall & 3 & 2 & 2 & 2 \\
\hline Diaphragm & 1 & & & \\
\hline Vena cava & 2 & & & \\
\hline Pleuropneumonectomy & 1 & & & \\
\hline Atrium & & & & \\
\hline Resection R0:R1:R2 & $7: 9: 1$ & $6: 6: 2$ & $4: 1: 2$ & $1: 1: 2$ \\
\hline \multicolumn{5}{|l|}{ Chemotherapeutic agents } \\
\hline Cisplatinum $100 \mathrm{mg} / \mathrm{m}^{2}$ & 16 & 14 & 7 & 4 \\
\hline Doxorubicin & 8 & 10 & 5 & 0 \\
\hline \multicolumn{5}{|l|}{ Perfusion temperature } \\
\hline$\leq 41.8^{\circ} \mathrm{C}$ & 6 & 6 & & 2 \\
\hline$>41.8^{\circ} \mathrm{C}$ & 11 & 8 & 7 & 2 \\
\hline
\end{tabular}

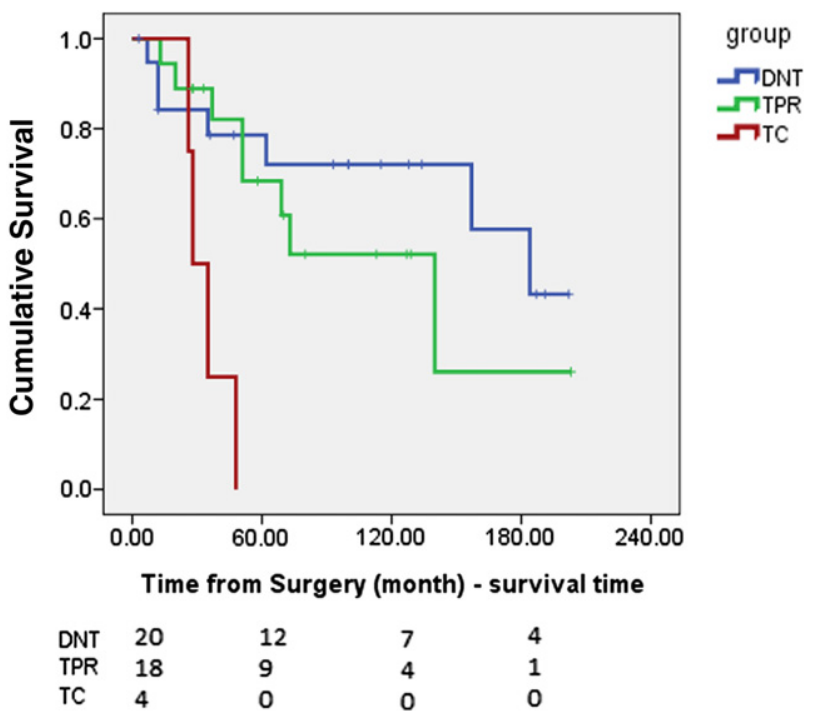

FIGURE 1. Overall survival for thymoma (de nono stage IVa thymoma $[D N T]$ and thymoma with pleural relapse $[T P R])$ and thymic carcinoma $(T C)(\mathrm{n}=35)$.

Thymoma. Deaths occurred from 7 months to as long as 14 years after surgery equally in both groups, only 4 of them owing to systemic disease progression (7, 30, 51, and 106 months after surgery). One died of a second primary neoplasm, 1 is still alive with widespread metastases, and 2 have probably been cured of early-stage malignant disease (lung and prostate). Thus the rate of second neoplasms in our series was $13 \%$. Two deaths in myasthenic patients were attributed to pneumonia, and 2 may have been due to thymus-related syndromes. One patient died at the age of 82 years of right heart failure. Interestingly, none of the 14 myasthenic patients had complete neurologic remission.

The median follow-up for all patients was 62 months (range, 3.5-202 months). The 5, 10, and 15-year overall survivals for DNT and TPR were $80.8 \%, 72.7 \%$, and $58.2 \%$ (DNT) and 66.7\%, 55.6\%, and 27.8\% (TPR) (Figure 1). The median survival was 184 months $(95 \%$ confidence interval, 120.5-247.5) for DNT and 140 months (95\% confidence interval, 34.3-245.7) for TPR. The 5- and 10-year progression-free survivals were $60.6 \%$ and $43.3 \%$ for DNT and $47.6 \%$ and $17.9 \%$ for TPR (Figure 2). The 10-year disease-specific survivals for DNT and TPR were $79 \%$ and $87.5 \%$, respectively (Figure 3 ).

Using the Mann-Whitney test, only the extent of resection (complete responders vs incomplete responders) predicted disease-free survival $(Z=-3.71 ; P<.001)$. Local control was related to the same variable using the $\chi^{2}$ test (complete responders, 25\% relapse, vs incomplete responders, $65 \% ; P=.015)$.

\section{DISCUSSION}

This retrospective study establishes the feasibility and safety of HPCP after resection in TET patients with 


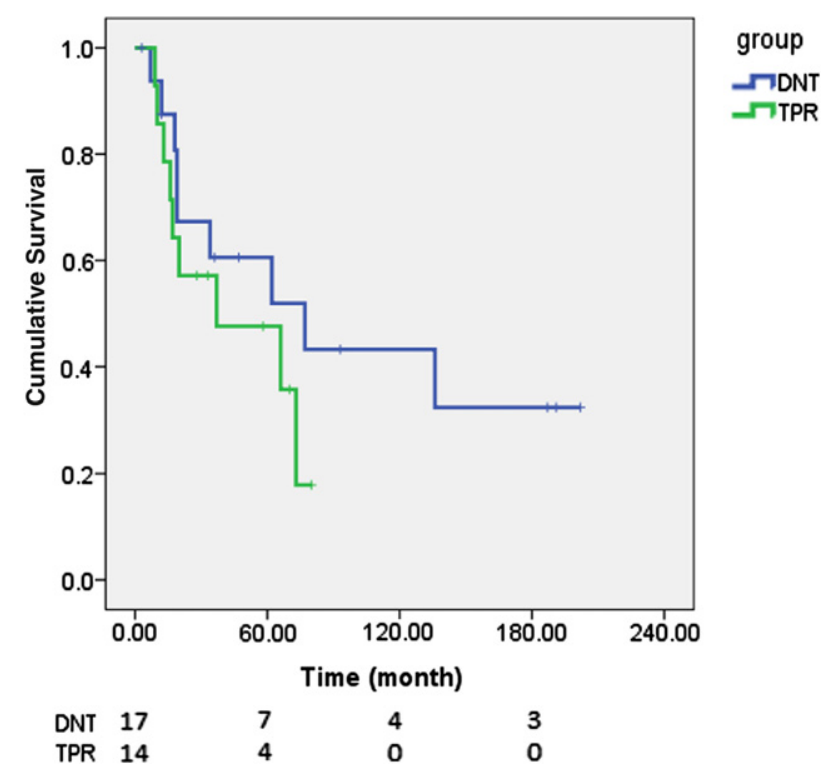

FIGURE 2. Progression-free survival for de novo stage IVa thymoma $(D N T, \mathrm{n}=17)$ and thymoma with pleural relapse $(T P R, \mathrm{n}=14)$.

pleural spread. The combined treatment was associated with no systemic toxicity, $2.5 \%$ 90-day mortality, and a major morbidity of $12.5 \%$. The 10 -year overall survival of $73 \%$ is among the best ever reported. Similar results were achieved by Huang and associates ${ }^{11}$ in a series of 18 patients undergoing extensive resections. These rates are superior to the $40 \%$ figure commonly found in the literature. ${ }^{18-20}$ Unfortunately, the recommendation to perform extrapleural pneumonectomy was recently met with frustrating results: 90 -day mortality of $29 \%$,

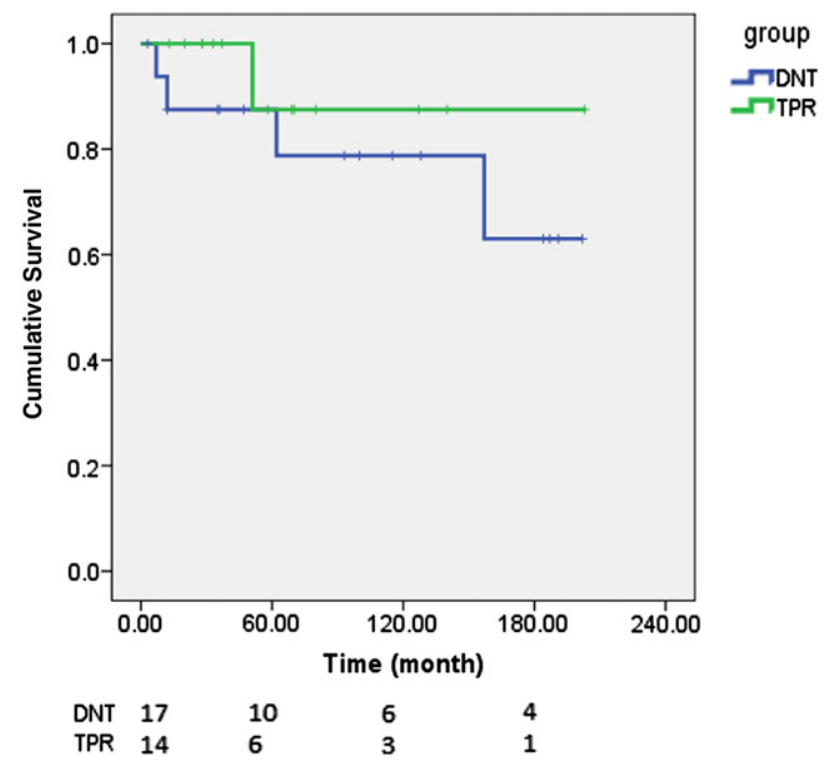

FIGURE 3. Cause-specific survival for de novo stage IVa thymoma $(D N T)$ and thymoma with pleural relapse (TPR). major morbidity of $47 \%$, and 10 -year overall survival of $30 \%{ }^{10}$

Reports pertaining to stage IVa thymoma are difficult to compare. Patients included in such small studies usually differ in many parameters. For example, in our series the incidence of myasthenia was $48 \%$, whereas it was $29 \%$ in the report by Fabre and associates ${ }^{10}$ and $0 \%$ in that of Huang and colleagues. ${ }^{11}$ One must recall that myasthenia and its treatment may contribute to excessive operative morbidity and mortality, ${ }^{10}$ as well as to late deaths. Without the knowledge of the causes for late mortality, results are difficult to interpret. Thus in our series only 4 patients died of disease progression, whereas all other late deaths were not cause specific, including 2 probably attributed to thymus-related syndromes and 1 to a second primary neoplasm.

Another confounding factor is the follow-up periods. Some studies have reported only mean follow-up period, which is usually meaningless. In others, the median follow-up varies from less than 1 year to as much as 98 months, ${ }^{8}$ although the last figure is probably miscalculated. With a minute number of patients at risk at the 5- and 10 -year points, the actuarial survival figures may differ considerably from the actual rates.

Other factors that may affect survival, and certainly local relapse, are the number of pleural implants and tumor burden. Two studies addressed the first issue. Overall survival was found to be significantly better in patients who had single versus multiple relapse lesions ${ }^{2}$ or 1 to 2 versus 3 or more pleural implants. ${ }^{3}$ In our series, only 6 patients had fewer than 3 lesions and the majority had numerous implants. As expected, this variable had no statistically significant effect on overall survival and progression-free survival as well as on local control. Tumor burden has not been studied previously as a possible prognosticator. In our study, this variable had no effect on the outcome. Local control may be affected also by additional variables related to tumor biology (classification, interval from thymectomy, chest wall invasion, and response to previous treatments), the significance of which is difficult to assess in small studies. Operative variables possibly play a role. Completeness of resection is certainly important in stages II and III and perhaps also in stage IVa, as some studies discussed here have demonstrated. In our study, it had a significant effect on local control and progression-free survival. Although we, like others, doubt whether $\mathrm{R} 0$ resection is indeed achievable when widespread pleural seeding is present, it seems that the combined surgical-pathologic resection status correlates with some end points. We also attempted to evaluate variables pertaining to our specific management. Of those, only the perfusion temperature may play a role. The specific chemotherapeutic agents used and their concentration failed to show any impact on the end points studied. In a pleural and abdominal perfusion study in patients with mesothelioma, Tilleman and associates ${ }^{21}$ have used 
cisplatinum doses as high as $225 \mathrm{mg} / \mathrm{m}^{2}$. Doses higher than $100 \mathrm{mg} / \mathrm{m}^{2}$ could be tested also in thymoma patients.

The results of our study highlight a few interesting points: (1) Patients may survive for prolonged periods despite disease relapse. (2) Freedom from relapse does not ensure longevity owing to late deaths from nonthymomatous causes. (3) Myasthenia in patients with stage IVa disease tends to persist. (4) There is a moderate rate of contralateral pleural relapse. (5) More than $10 \%$ of the patients are expected to have a second primary neoplasm. Pleuropneumonectomy, or extrapleural pneumonectomy in myasthenic patients and after neoadjuvant chemotherapy, may be associated with considerable mortality. Considering the entire spectrum of these facts along with life quality, we believe that the approach proposed by us, that is, lung-preserving resection plus HPCP, may emerge as the preferred treatment for thymoma patients with pleural spread.

Our study has some of the usual weaknesses of a singlecenter nonrandomized study: selection bias and confounding variables. The fact that the response rate to preoperative chemotherapy in thymoma patients was $88 \%$ points to a selection bias from referral centers. The contribution of various preoperative and postoperative modalities to survival could not be analyzed owing to a great variation in means and timing. A large prospective multicenter trial may overcome these shortcomings.

\section{References}

1. Detterbeck FC, Parsons AM. Thymic tumors: a review of current diagnosis, classification, and treatment. In: Pearson's thoracic \& esophageal surgery. 3rd ed. Philadelphia: Churchill Livingstone; 2008:1589-614.

2. Margaritora S, Cesario A, Cusamano G, Lococo F, Porziella V, Maecci E, et al. Single center 40-year results of redo operation for recurrent thymoma. Eur J Cardiothorac Surg. 2011;40:894-901.

3. Yano M, Sasaki H, Moriyama S, Hikosaka Y, Yokota K, Masaoka A, et al. Number of recurrent lesions is a prognostic factor in recurrent thymoma. Interac Cardiovasc Thorac Surg. 2011;13:21-4.

4. Kunitoh H, Tamura T, Shibata T, Nakagawa K, Takeda K, Nishiwaki Y, et al. A phase II trial of dose-dense chemotherapy in patients with disseminated thymoma: report of a Japan Clinical Oncology Group trial (JCOG 9605). Br J Cancer. 2009;101:1549-54.

5. Rena O, Mineo TC, Casadio C. Multimodal treatment for stage IVA thymoma: a proposable strategy. Lung Cancer. 2011;76:89-92.

6. Sugie C, Shibamoto Y, Ikeya-Hashizume C, Ogino H, Ayakawa S, Tomita N, et al. Invasive thymoma: post operative mediastinal irradiation and low-dose entire hemithorax irradiation in patients with pleural dissemination. J Thorac Oncol. 2008;3:75-81.

7. Belcher E, Hardwick T, Lal R, Marshall S, Spicer J, Lang-Lazdunski L. Induction chemotherapy, cytoreductive surgery and intraoperative hyperthermic pleural irrigation in patients with stage IVA thymoma. Interac Cardiovasc Thorac Surg. 2011;12:744-8.

8. Lucchi M, Davini F, Ricciardi R, Duranti L, Boldrini L, Palmiero G, et al. Management of pleural recurrence after curative resection of thymoma. J Thorac Cardiovasc Surg. 2009;137:1185-9.

9. Wright CD. Pleuropneumonectomy for the treatment of Masaoka stage IVA thymoma. Ann Thorac Surg. 2006;82:1234-9.

10. Fabre D, Fadel E, Mussot S, Mercier O, Petkova B, Besse B, et al. Long-term outcome of pleuropneumonectomy for Masaoka stage IVa thymoma. Eur J Card Thorac Surg. 2011;39:e133-8.

11. Huang J, Rizk NP, Travis WD, Seshan VE, Bains MS, Dycoco J, et al. Feasibility of multimodality therapy including extended resections in stage IVA thymoma. J Thorac Cardiovasc Surg. 2007;134:1477-84.
12. Ishikawa Y, Matsuguma H, Nakahara R, Suzuki H, Ui A, Kondo T, et al. Multimodality therapy for patients with invasive thymoma disseminated into the pleural cavity: the potential role of extrapleural pneumonectomy. Ann Thorac Surg. 2009;88:952-7.

13. Carry PY, Brachet A, Gilly FN, Sayag AC, Petit PY, Rochette C, et al. A new device for the treatment of pleural malignancies: intrapleural chemohyperthermia-preliminary report. Oncology. 1993;50:348-52.

14. Rusch V, Saltz I, Vankatraman E, Ginsberg R, McCormack P, Burt M, et al. A phase II study of pleurectomy/decortications followed by intrapleural and systemic chemotherapy for malignant pleural mesothelioma. J Clin Oncol. 1994; 12:1156-63.

15. Matzuzaki Y, Shibata K, Yoshioka M, Inoue M, Sekiya R, Pnitsuka T, et al. Intrapleural perfusion hyperthermo-chemotherapy for malignant pleural dissemination and effusion. Ann Thorac Surg. 1995;59:127-31.

16. Yellin A, Simansky DA, Paley M, Refaely Y. Hyperthermic pleural perfusion with cisplatinum: early clinical experience. Cancer. 2001;92:2197-203.

17. Refaely Y, Simansky DA, Paley M, Gottfried M, Yellin A. Resection and perfusion thermochemotherapy: a new approach for the treatment of thymic malignancies with pleural spread. Ann Thorac Surg. 2001;72:366-70.

18. Maggi G, Casadio C, Cavello A, Cianci R, Molinatti M, Ruffini E. Thymoma: results of 241 operated cases. Ann Thorac Surg. 1991;51:152-6.

19. Kondo K, Monden Y. Therapy for thymic epithelial tumors: a clinical study of 1,320 patients from Japan. Ann Thorac Surg. 2003;75:878-85.

20. Lucchi M, Ambrogi MC, Duranti L, Basolo F, Fontanini G, Angeletti CA, et al Advanced stage thymoma and thymic carcinoma: results of multimodality treatment. Ann Thorac Surg. 2005;79:1840-4.

21. Tilleman TR, Richards WG, Zellos L, Johnson BE, Jaklitsch MT, Mueller J, et al Extrapleural pneumonectomy followed by intracavitary intraoperative hyperthermic cisplatinum with pharmacologic cytoprotection for treatment of malignant pleural mesothelioma: a phase II prospective study. J Thorac Cardiovasc Surg. 2009;138:405-11.

\section{Discussion}

Dr Joshua R. Sonett (New York, NY). Dr Yellin, thank you for the delivery of your manuscript and your slides over a month before the presentation.

I have nothing to disclose except to personally thank you for helping bring this modality to Columbia over 7 years ago. I am glad to say that the patient you introduced this therapy to at Columbia is doing quite well.

Your group has to be complimented as one that thought outside the box about locoregional treatment before it was fashionable and is assessing it quite soberly and objectively even as you advocate it as a possible standard.

I have some general points of discussion and 3 questions. Your best results, as one might expect, were in R0 resections, as with virtually all thymic resection series. Many would thus argue that these patients do not need this therapy. Can you tackle this question and also help sort out how to definitively prove this is a significant therapeutic advance, especially given the overall slow progression of many of these patients and the ability to give subsequent systemic chemotherapy?

Induction chemotherapy for locally advanced thymoma appears to be effective in reducing tumor burden and increasing $\mathrm{R} 0$ resections. Would you at present advocate or consider systemic chemotherapy before your operative treatment with known stage IV disease to increase your R0 resection preoperatively?

Finally, at Columbia we have pretty much copied your model for advanced thymoma. However, in pleural mesothelioma we have developed a model of repeated intrapleural dosing. If chemotherapy given once intraoperatively is of probable but not proven value, why stop at a single dose? All conventional cancer chemotherapy is given repeatedly. Repetitive chemotherapy kills a greater 
fraction of cells as well as cells that have emerged from a chemorefractory state. We have thus far shown in patients with pleural mesothelioma that such chemotherapy can be given over a 2-month period via indwelling intrapleural catheters, repeated quite safely and easily. So should we consider this model for stage IV thymomas, followed by a final resection and heated chemotherapy?

I thank you and again congratulate you on your pioneering work.

Dr Yellin. Thank you, Dr Sonett, for your kind remarks and thoughtful input.

I personally doubt that R0 resection is indeed achievable, although formally that is the case. The philosophy behind the perfusion is to treat invisible small implants. R0 resection yielded the best results as far as local control was concerned, but it had no impact on overall survival. Unfortunately, the proof that perfusion has an advantage over any other modality requires a phase 3 study, which probably will never take place.

Preoperative chemotherapy in our patients was given sporadically in an unplanned manner. It was not in a neoadjuvant setting. From our data, it seemed effective but had no impact on the results. Nevertheless, faced with an invasive mediastinal thymoma or bulky implants, I would recommend neoadjuvant therapy.

The third question is certainly very interesting. Before addressing it, I have to mention a few facts. First, pharmacokinetic studies have shown that in the perfusion setting, cisplatinum serum concentration is almost 0 after 24 hours, which allows for a second dose. Second, cisplatinum absorption is higher in patients undergoing limited resection compared with those who undergo extrapleural pneumonectomy. Third, perfusion is followed very quickly by severe adhesions. Therefore, I believe that we could indeed repeat the dose, but only in a time frame of about a week, not very much longer. We certainly should consider it. Thank you for the idea.

Dr David J. Sugarbaker (Boston, Mass). You chose platinum and doxorubicin as your 2 drugs. In terms of dosing, inasmuch as there are no data on the appropriate dose of chemotherapeutic agents placed intrathoracically, do you think that you might be better served by performing a phase 1 trial to establish the maximum tolerated dose? We have done that with mesothelioma, as presented earlier today. We achieved a dose that was several times higher than the dose that is given intravenously, 225 versus $100 \mathrm{mg} / \mathrm{m}^{2}$. If you remember Hill's postulates on the effectiveness of chemotherapy, effective chemotherapy improves survival as one is able to increase the concentration and/or dose of the drug.

I have 2 questions. First, you selected doxorubicin and platinum. In the United States, that is not a commonly administered chemotherapeutic regimen for stage IV thymoma. Second, do you think that additional studies of the phase 1 type which would allow for dose escalation and triplets would allow you to maximize the effect of chemotherapy?

Dr Yellin. We chose cisplatinum and doxorubicin because those are 2 of the most common drugs given for thymoma at large and those are the drugs that worldwide have the largest experience. We know most about the pharmacokinetics, the side effects, and so on. We were concerned with the higher doses you have reached because, with an intact pleura, we should expect higher serum levels, and therefore toxicity could be a bit higher than is seen in other studies.

Dr Sugarbaker. Are you trying to get all macroscopic disease resected, in which case I would assume that the pleura was also resected? Is that not the case?

Dr Yellin. Not necessarily. In most cases we did not perform a total pleurectomy, only a partial pleurectomy. Certainly, the visceral pleura was intact and part of the mediastinal pleura was intact and the diaphragmatic pleura stayed intact. We had enough of an absorption area to increase serum levels.

Dr Sugarbaker. Do you think that all that retained pleura, which is invariably seeded with tumor cells, may be responsible somewhat for the survival that you noted? Do you think you might be better off to do a complete, radical pleurectomy in these cases if you are not going to do an extrapleural pneumonectomy?

Dr Yellin. Perhaps, but the survival results are at least comparable with those with extrapleural pneumonectomy, and therefore I am not sure it is indeed required.

Dr Mark J. Krasna (Neptune, NJ). I enjoyed the presentation and again congratulate you and your group for pushing this forward for many, many years.

As we heard this morning in the mesothelioma talk by Dr Sugarbaker, it sounds like your group is now using it, and now you are talking about putting it into a phase 2 study. The message that I would like to understand is, first, are you ready to say to us that in prime time we should do this? Are you advocating that off protocol we should be using intrapleural chemotherapy for the stage IV diseases, whether you do it as an extrapleural pneumonectomy or an en bloc macroscopic resection? My second question to both you and Dr Sugarbaker is, if not, can we get a cooperative group study? I know many years ago we tried to do a cooperative group study for mesothelioma to test your phase 2 hypothesis, David. Is it time to do either a national or international phase 2 or phase 3 , either in the thymic group or the mesothelioma?

Dr Yellin. I certainly advocate it, but, unfortunately, the International Thymic Malignancy Interest Group has decided that another venue is maybe preferred owing to technical difficulties and institutional review board problems and so on. I believe this is the best thing to do, but certainly there are many ways to skin a cat.

Dr Sugarbaker. I would respond to your questions, Mark, with the following. This study in particular has relatively small numbers, and I do not think we can make conclusions as to standard of care from such a study. I think excellent groundwork has been laid in single institutional trials for a multi-institutional feasibility trial to see whether this is exportable. However, with all of the discussion going on about the performance of macroscopic complete resection by extrapleural pneumonectomy or pleurectomy by those who think that those 2 operations are done for the same indication, which they are not, it certainly indicates that, just like with lung transplantation that we just heard, esophageal cancer, and lobectomies earlier in this meeting, not everybody who does extrapleural pneumonectomy, particularly at low frequencies, is going to have the same perioperative mortality. The recent MARS (Mesothelioma And Radical Surgery) trial had an almost $20 \%$ operative mortality, an extremely small number of patients, and it really defies any conclusions at all about the appropriate procedure. As I mentioned this morning, depending on disease distribution, either 
pleurectomy/decortication or extrapleural pneumonectomy, as long as you are getting $3 \%$ or $4 \%$ operative mortality for the pneumonectomies, should be applied to get a macroscopic complete resection. What we need to do is to move on, as you are suggesting and as the author here is suggesting, to determine what the better extender of surgical margin is in these 2 tumors that recur locally. What is the best regimen? I think that is where surgeons and oncologists should be going. We should drop this idea as to which operation is better, because it is really 2 different operations for 2 different indications and distributions of disease.

Access to The Journal of Thoracic and Cardiovascular Surgery Online is reserved for print subscribers!

Full-text access to The Journal of Thoracic and Cardiovascular Surgery Online is available for all print subscribers. To activate your individual online subscription, please visit The Journal of Thoracic and Cardiovascular Surgery Online, point your browser to http://www.mosby.com/itcvs, follow the prompts to activate your online access, and follow the instructions. To activate your account, you will need your subscriber account number, which you can find on your mailing label (note: the number of digits in your subscriber account number varies from 6 to 10). See the example below in which the subscriber account number has been circled:

\section{Sample mailing label}

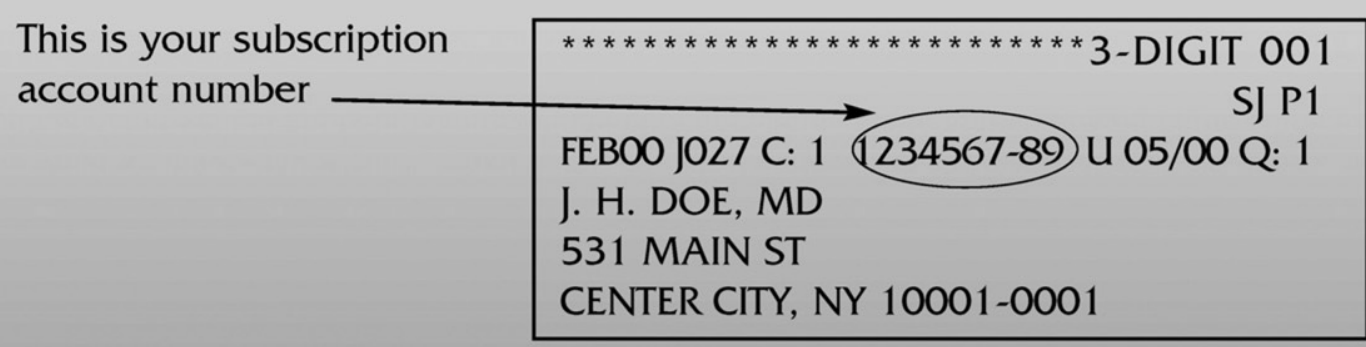

Personal subscriptions to The Journal of Thoracic and Cardiovascular Surgery Online are for individual use only and may not be transferred. Use of The Journal of Thoracic and Cardiovascular Surgery Online is subject to agreement to the terms and conditions as indicated online. 